\title{
Desempenho de dois pomares adultos de laranjeira 'Pêra' no oeste de Santa Catarina, Brasil
}

\author{
Eduardo Cesar Brugnara' e Thomaz Palma Rocha Andrade²
}

\begin{abstract}
Resumo - O cultivar de laranjeira 'Pêra' (Citrus sinensis (L.) Osb.) é o mais importante no Brasil, devido à sua boa adaptação no sudeste do país e à qualidade do seu suco. Porém, como é suscetível à tristeza dos citros, doença que é mais severa em climas frios - como o subtropical, que ocorre no sul do Brasil -, seu cultivo nessa região é limitado. O objetivo deste trabalho foi avaliar a potencialidade da laranjeira 'Pêra Bianchi' para o cultivo em Santa Catarina. Foram avaliados dois pomares adultos de 'Pêra Bianchi' localizados no oeste do estado. Durante duas safras, avaliaram-se o tamanho das plantas, a produção de frutos e a qualidade dos frutos (tamanho e características do suco). A laranjeira 'Pêra Bianchi' apresentou produtividade satisfatória, média equivalente a 42 e $45 \mathrm{t} \mathrm{ha}^{-1}$, e qualidade de suco adequada aos padrões de mercado. Porém, grande parte dos frutos produzidos não apresentou tamanho adequado à comercialização como fruta de mesa. Foi observada considerável variabilidade entre plantas no mesmo pomar quanto à produtividade e tamanho dos frutos.
\end{abstract}

Termos para indexação: Citrus sinensis (L.) Osb.; tamanho de frutos; tristeza dos citros.

\section{Performance of two mature 'Pêra' sweet orange orchards in West Santa Catarina, Brazil}

Abstract - The sweet orange cultivar 'Pêra' [(Citrus sinensis L.) Osb.] is the most important in Brazil due to its good adaptation in the Southeast region and the quality of its juice. However, it is susceptible to citrus tristeza, a disease that is more severe in cold climates such as subtropical ones. Thus, its cultivation in this region is limited. The objective of this study was to evaluate the potentiality of 'Pêra Bianchi' orange for cultivation in the Santa Catarina state. Two adult 'Pêra Bianchi' orchards located in the west of the state were evaluated. Plant size, fruit production and its quality (size and juice characteristics) were evaluated during two harvests. 'Pêra Bianchi' orange presented satisfactory yearly productivity, averaging the equivalent to 42 and $45 \mathrm{t}$ $\mathrm{ha}^{-1}$, and its juice quality was adequate to market standards. However, a large portion of the fruit produced is not adequate in size for commercialization as fresh fruit. Regarding fruit productivity and size, there was a substantial variability among plants in the same orchard.

Index terms: Citrus sinensis (L.) Osb.; fruit size; citrus tristeza virus.

\section{Introdução}

No estado de Santa Catarina, na safra 2014/2015, cerca de 1.400 produtores cultivavam em torno de $1,5 \mathrm{mil}$ hectares de laranjeira (Citrus sinensis (L.) Osb.), produzindo 22 mil toneladas de frutos (GOULART JUNIOR et al., 2016). A cultura divide com a videira a liderança no ranking de importância econômica e social das fruteiras no oeste e extremooeste catarinense.

A laranjeira 'Pêra' é extensamente cultivada no Brasil por sua excelente qualidade para industrialização e consumo fresco (KOLLER \& SOPRANO, 2013a). A maturação ocorre a partir de agosto no Rio Grande do Sul (SARTORI et al., 2002) e setembro em Santa Catarina
(KOLLER \& SOPRANO, 2013a).

Na região leste de Santa Catarina, Koller \& Soprano (1993) avaliaram a produção e o crescimento das três primeiras safras de laranjeiras. A laranjeira 'Pêra Premunizada' apresentou menor crescimento em altura que 'Hamlin' e 'Rubi' e menor área de projeção da copa que 'Rubi', 'Valência' e 'Hamlin'. A produção de frutos acumulada foi de $89,7 \mathrm{~kg} \mathrm{planta}^{-1}$, inferior a 'Hamlin', 'Tobias' e 'Valência'. Por outro lado, a produção por $\mathrm{m}^{2}$ de copa não diferiu da 'Rubi' e da 'Valência', que são os cultivares mais importantes no oeste e no extremo-oeste do estado. No norte do Paraná, três clones de laranja 'Pêra' foram avaliados por 14 safras. A produção média variou de 131 a $164 \mathrm{~kg}$ planta $^{-1}$, equivalente a $30-40 t \mathrm{ha}^{-1}$. A massa média de frutos ficou entre 150 e $160 \mathrm{~g}$ (TAZIMA et al., 2010).

A laranjeira 'Pêra' é suscetível à tristeza dos citros, doença causada pelo vírus CTV (Citrus tristeza virus), que ocorre em Santa Catarina juntamente com seu vetor, o pulgão-preto Toxoptera citricida Kirk.. A doença afeta diversos cultivares copa e porta-enxertos, inclusive a laranjeira 'Pêra'. Os porta-enxertos utilizados atualmente, limoeiro 'Cravo' ( $C$. limonia Osb.) e híbridos de trifoliata (Poncirus trifoliata (L.) Raf.), são resistentes ao vírus. Na 'Pêra', a doença pode causar a formação de caneluras (stem pitting), que são depressões no lenho, atrofiamento da planta, folhas pequenas, clorose semelhante a deficiências de zinco, • 
manganês e outros nutrientes. Ocorre, também, a formação de frutos miúdos. Os clones de laranja Pêra utilizados hoje são premunizados com estirpes fracas do vírus. Porém, a doença é mais severa em climas amenos como o de Santa Catarina, resultando em produção de frutos de tamanho reduzido a partir do sexto ano de idade, e intensificação dos demais sintomas da doença com o aumento da idade das plantas (KOLLER \& SOPRANO, 2013a; THEODORO \& KOLLER, 2013).

Este estudo de casos foi realizado com vistas a explorar a potencialidade da laranjeira 'Pêra' em dois pomares do oeste de Santa Catarina, por meio de levantamento de índices técnico-produtivos, com fins de orientar futuras linhas de pesquisa, visto que poucos dados estão disponíveis sobre esse cultivar para os tipos climáticos $\mathrm{Cfa}$ e Cfb de Köppen, no sul do Brasil.

\section{Material e métodos}

Os objetos deste estudo de casos foram dois pomares de laranjeira localizados em clima Cfa. O clone da copa é 'Pera Bianchi' premunizado (C. sinensis (L.) Osb.), e o porta-enxerto é a tangerineira 'Cleópatra' (C. reshni Hort. ex Tan.), ambos provenientes do Instituto Agronômico do Paraná. O estudo contemplou as safras agrícolas 2014/2015 e 2015/2016. O pomar 1 foi implantado em 2004, em Xaxim/SC, altitude de 592 $\mathrm{m}$, em cambissolo, com plantas espaçadas de $6 \times 3 \mathrm{~m}$. Está inserido em uma área contígua de laranjeiras e tangerineiras (C. spp.) de 10ha, sendo 1,5ha de 'Pera Bianchi'. O manejo realizado pelo proprietário consiste em adubação anual com $1 \mathrm{~kg}$ planta $^{-1}$ de fertilizante organomineral NPK 10-10-10, e pulverizações esporádicas de sais de cobre. 0 pomar 2, plantado em 2002, é localizado em Chapecó/SC, em altitude de $589 \mathrm{~m}$, em latossolo vermelho, com plantas espaçadas de $7 \times 3,5 \mathrm{~m}$. O pomar de 'Pera Bianchi' ocupa área de 1,0ha e compõe uma área contígua de laranjeiras de 6,0ha. O manejo dessas duas safras consistiu em aplicações anuais de calcário calcítico (1 t ha $\left.{ }^{-1}\right)$, duas aplicações anuais de fertilizante NPK 10-10-10 (1 kg planta $^{-1}$ ), aplicações mensais - de agosto a dezembro - de fertilizante foliar $(\mathrm{Mg}$, $\mathrm{S}, \mathrm{B}, \mathrm{Cu}, \mathrm{Fe}, \mathrm{Mn}, \mathrm{Mo}$ e $\mathrm{Zn}$ ), hidróxido de cobre e fosfito (ácido fosforoso). Ambos os pomares apresentavam no início do trabalho sintomas típicos de tristeza dos citros (caneluras nos ramos).

Em 2015, foram tomadas duas linhas de plantas no interior de cada pomar, totalizando 17 e 20 plantas contíguas, nos pomares 1 e 2 , respectivamente, que constituíram as amostras de plantas. Dessas plantas, nas safras 2014/2015 e 2015/2016, em agosto, os frutos produzidos por cada planta foram colhidos, classificados mecanicamente por diâmetro, em três classes (pequenos (P), médios (M) e grandes (G)), de acordo com o procedimento utilizado rotineiramente pelos respectivos citricultores. As classes P, M e G são carac- terizadas na Figura 1. Em cada classe, foram tomados 75 frutos ao acaso para determinar o diâmetro dos frutos na região equatorial.

Quantificou-se o número, a massa total e a massa média dos frutos produzidos por planta em cada classe de tamanho. Foi calculada a produtividade por hectare com base no espaçamento. Em agosto de 2015, foram avaliadas a largura e a altura da copa, com as quais se calculou o volume de copa (altura multiplicada pelo quadrado do diâmetro médio). Na safra 2014/2015, também foram realizadas análises para determinar o conteúdo de sólidos solúveis, a acidez, o ratio e o rendimento de suco dos frutos de cada classe e planta. Os dados das plantas, da produtividade e da qualidade dos frutos foram anali-
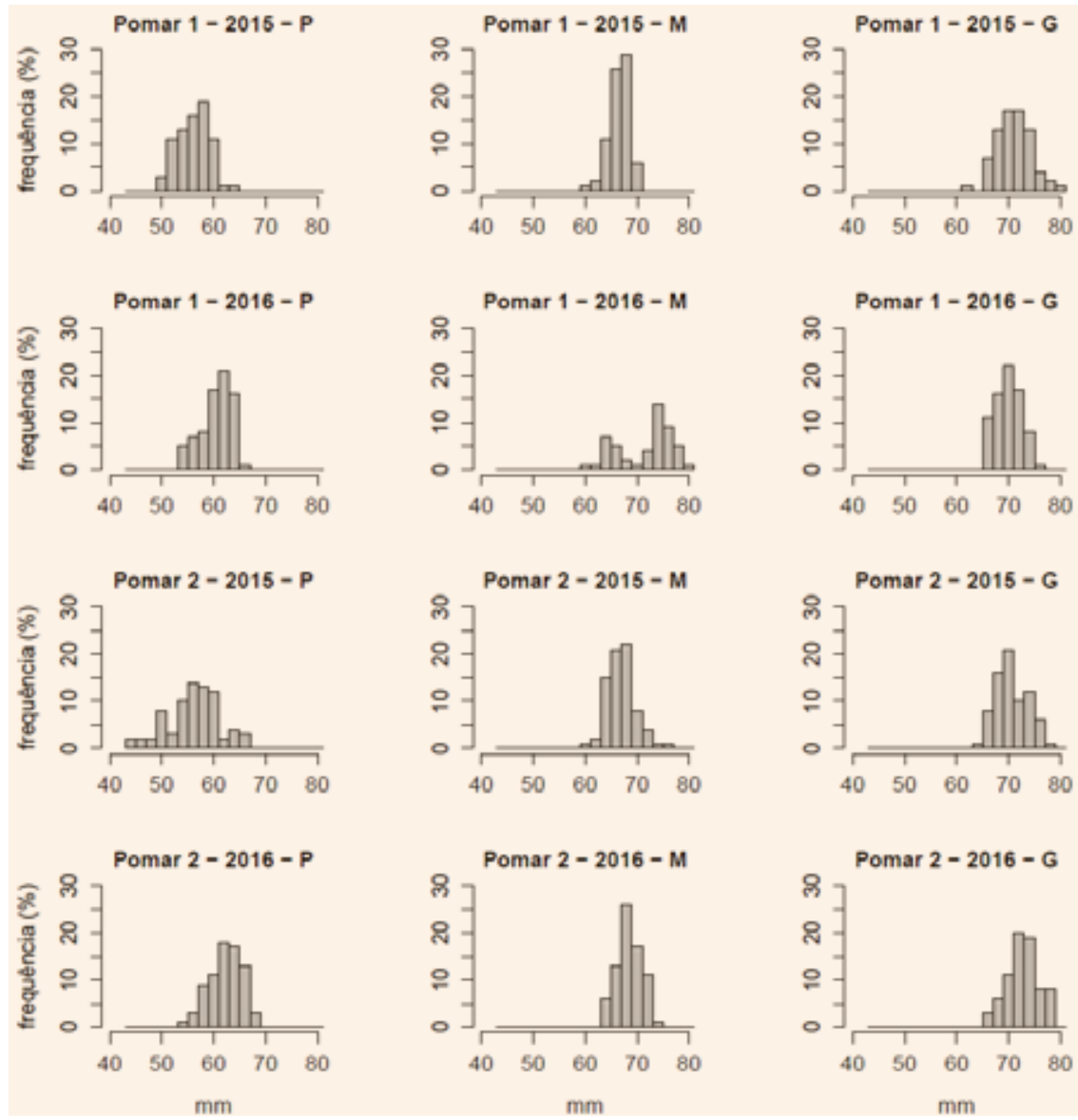

Figura 1 - Distribuição de frequência de frutos de laranjeira 'Pêra Bianchi' de dois pomares por classe de diâmetro ( $\mathrm{mm}$ ) após classificação mecânica (tamanhos P, M e G), em dois anos (2015 e 2016). As classes $P$ (pequenos), M (médios) e $G$ (grandes) foram obtidas pela classificação mecânica por diâmetro. A calibração do equipamento foi diferente entre locais e anos

Figure 1 - Frequency distribution of 'Pêra Bianchi' orange fruit of two orchards per diameter class ( $\mathrm{mm}$ ) after mechanical classification (sizes $P, M$ and $G$ ), in two years (2015 and 2016). The classes $P$ (small), $M$ (medium) and $G$ (large) were obtained by mechanical classification by diameter. The calibration of the equipment was different between locations and years 
sados com o auxílio de estatística descritiva. Os dados de classe dos frutos também foram submetidos à análise de frequências através de histogramas.

\section{Resultados e discussão}

O tamanho dos frutos em cada categoria de tamanho $(P, M$ e $G)$, após classificação mecânica, é caracterizado na Figura 1, que ilustra a distribuição dos frutos por classe de diâmetro. Houve pequena variação entre os resultados dos dois pomares e entre as safras, pois a regulagem da máquina classificadora não foi uniformizada entre os pomares e safras, mas seguiu o adotado pelos produtores. Na categoria P predominaram frutos com diâmetros entre 50 e $60 \mathrm{~mm}$ em 2015 e 57 a $65 \mathrm{~mm}$ em 2016, em ambos os pomares. A título de referência, a Companhia de Entrepostos e Armazéns Gerais de São Paulo (Ceagesp), que normatiza a classificação de citros, utiliza como parâmetros de classificação de laranjas comuns por tamanho os diâmetros equatoriais de 65 e $71 \mathrm{~mm}$ (CEAGESP, 2011). Frutos maiores que $71 \mathrm{~mm}$ são classificados como grandes e os menores que 65 como pequenos. Nos casos em estudo, os frutos da categoria P seriam classificados como pequenos. Já os da categoria $\mathrm{M}$ mediram, predominantemente, de 63 a $71 \mathrm{~mm}$ em 2015. No caso dos frutos M de 2016 e dos G, houve uma discordância com as classes da Ceagesp. A variação observada dentro da classe e a sobreposição entre classes podem estar relacionadas ao formato alongado do fruto (altura maior que diâmetro), que dificulta a correta separação na classificadora mecânica. Porém, os citricultores comercializam os frutos M e G no mercado in natura.

Os menores frutos pesaram $77,5 \mathrm{e}$ $56,5 \mathrm{~g}$ nos pomares 1 e 2 , respectivamente, ambos na safra 2014/2015. Da mesma forma, os maiores frutos alcançaram 261,2 e $270,8 \mathrm{~g}$. A massa média dos frutos foi 143 e $145 \mathrm{~g}$ nos pomares 1 e 2, respectivamente (Tabela 1). Uma das plantas produziu frutos que pesaram em média apenas 109g enquanto os de outra pesaram $200 \mathrm{~g}$, evidenciando a considerável variabilidade entre plantas. Não foram encontrados na literatura dados de massa média de frutos da 'Pêra' produzidos nas regiões de clima subtropical do sul do Brasil. Porém, em Cocal do Sul/SC, a laranjeira 'Hamlin' produziu, do segundo ao sétimo ano, frutos com massa média de $124,8 \mathrm{~g}$ (KOLLER et al., 2000), valor inferior ao observado para os pomares 1 e 2 , tanto para massa média global quanto para as categorias $\mathrm{G}$ e M. A média dos casos em estudo é também superior à de todos os clones de 'Pêra' testados em Cordeirópolis/SP por Schinor et al. (2009), mas semelhante ao observado em Londrina/
PR por Giampani et al. (2016) em vários clones de 'Pêra'. Dessa forma, não se pode afirmar que a massa média dos frutos em Chapecó e Xaxim é pequena, mas sim semelhante à das regiões tropicais.

O volume de copa das plantas apresentou variação de 12,76 a $43,6 \mathrm{~m}^{3}$ planta $^{-1}$ no pomar 1 e 33,5 a $66,5 \mathrm{~m}^{3}$ planta $^{-1}$ no pomar 2 (Tabela 1 ). O volume de copa por hectare, estimado com base no espaçamento de cada pomar e no volume de copa médio das plantas, foi $20.383 \mathrm{~m}^{3} \mathrm{ha}^{-1}$ no pomar $2 \mathrm{e}$ $16.900 \mathrm{~m}^{3} \mathrm{ha}^{-1}$ no pomar 1. Em Cordeirópolis/SP, plantas adultas de diversos clones de 'Pêra' apresentaram volume de copa equivalente a 5.828 até $20.914 \mathrm{~m}^{3}$ ha $^{-1}$ (SCHINOR et al., 2009). Já em Londrina/PR, observaram-se volumes médios de copa equivalentes a 5,3 até $20,8 \mathrm{~m}^{3} \mathrm{ha}^{-1} \mathrm{em}$ diversos clones avaliados aos 11 anos e meio (GIAMPA$\mathrm{NI}$ et al., 2016). Então, pode-se afirmar que nos casos em estudo o crescimento das plantas, em média, não é limitante.

A produção de frutos por planta é apresentada na Tabela 1. A planta mais produtiva de cada pomar produziu cerca de três vezes mais frutos, em massa, que a planta menos produtiva. A ocorrência de plantas produtivas em um pomar severamente atacado pela tristeza dos citros provavelmente se deve à ocorrência de estirpe(s) fraca(s) do *

Tabela 1 - Volume de copa, produtividade por planta global e por classe de tamanho de fruto, massa de frutos de mesa (MFM), massa média dos frutos (MMF) e eficiência produtiva da laranjeira 'Pêra Bianchi' em dois pomares do oeste de Santa Catarina - média das safras 2014/2015 e 2015/2016

Table 1 - Canopy volume, productivity per plant and fruit size class, table fruit mass (MFM), average fruit mass (MMF) and productive efficiency of 'Pêra Bianchi' orange tree in two orchards in the west of Santa Catarina-average of the 2014/2015 and 2015/2016 harvests

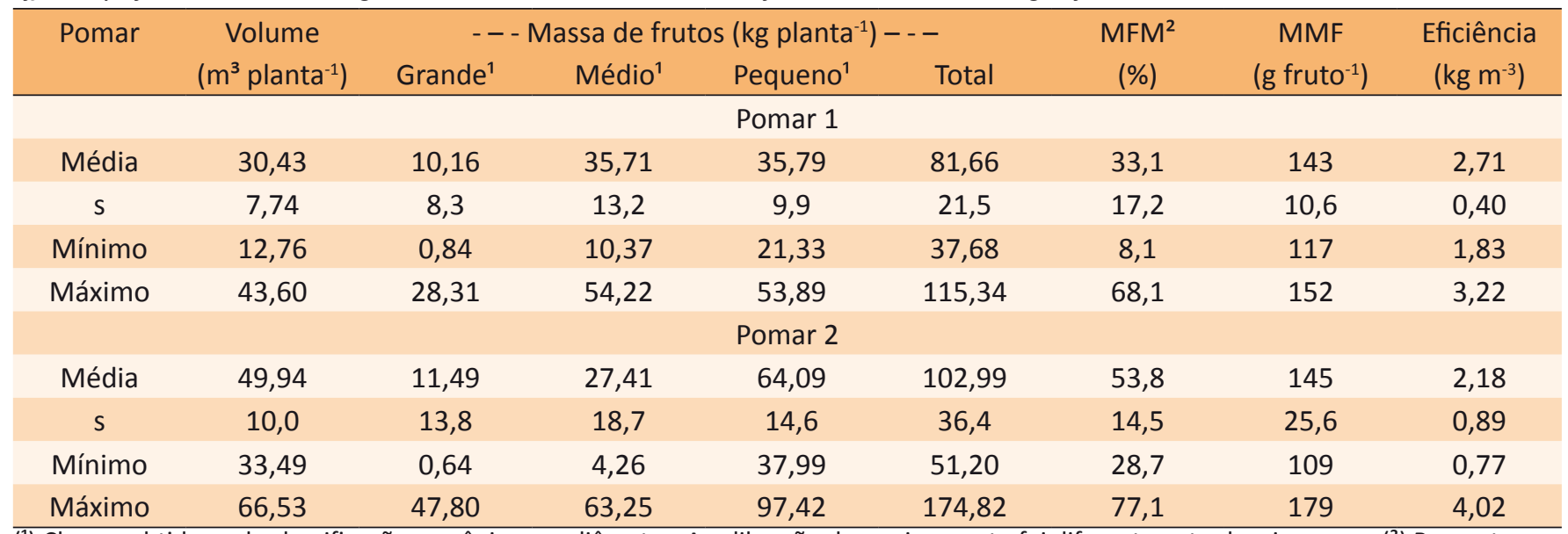

(1) Classes obtidas pela classificação mecânica por diâmetro. A calibração do equipamento foi diferente entre locais e anos. $\left({ }^{2}\right)$ Porcentagem da colheita (massa) com tamanho adequado a comercialização como fruta de mesa. 
vírus naquelas plantas, que impede(m) a ação das variantes severas (SOUZA \& MÜLLER, 2006). Em média, a produtividade foi de 81,66 e $102,99 \mathrm{~kg}$ planta $^{-1}$ nos pomares 1 e 2 , respectivamente. 0 montante equivale a 45 e $42 \mathrm{t} \mathrm{ha}{ }^{-1}$ (Figura 2). Em Alto Paraná/PR, foi observada produção média anual maior que 50 ha $^{-1}$ em um experimento com diversos tratamentos de manejo do solo (11을 e 12 ㅇaㅇ) (AULER et al., 2008); porém, em Londrina, de 18,6 a 49t ha-1 em uma avaliação de clones de 'Pêra' aos 11-13 anos (GIAMPANI et al., 2016). A laranjeira 'Valência' foi avaliada por Martins (2005) em Eldorado do Sul/RS, enxertada em citrumeleiro 'Swingle' e citrangeiro 'Troyer', produzindo anualmente, em média, 55kg por planta por ano, menos do que a 'Pêra' em Chapecó e Xaxim. Portanto, a laranjeira 'Pêra' pode ser considerada produtiva nos casos em estudo.

Em termos de produção relativa por volume de copa, a produção observada equivale a 2,71 e $2,18 \mathrm{~kg} \mathrm{~m}^{-3}$ de copa nos pomares 1 e 2, respectivamente. Valores de 1,91 a 3,51 $\mathrm{kg} \mathrm{m}^{-3}$ de copa foram observados por Azevedo et al. (2012), em plantas de mais de 16 anos de vários cultivares em Mogi Mirim/SP, e de 1,9 a $3,7 \mathrm{~kg} \mathrm{~m}^{-3}$ na região de Londrina, PR (GIAMPANI et al., 2016). Muitos daqueles valores de volume de copa e de produção da 'Pêra' foram superiores ao observado em Santa Catarina. Porém essa diferença não pode ser atribuída apenas à severidade da tristeza dos citros, pois outros fatores edafoclimáticos, bióticos ou de manejo podem ter afetado a produtividade e o crescimento.

Embora se tenha observado variação entre plantas nas quantidades e proporções de frutos produzidos de cada categoria de tamanho, na média das safras todas as plantas apresentaram pelo menos um fruto em cada categoria (Tabela 1). A produção de frutos de tamanho grande nas plantas do pomar 1 variou de 0,84 a $28,31 \mathrm{~kg}$ (planta ano $)^{-1}$ e no pomar 2, de 0,64 a 64,4kg (planta ano) ${ }^{1}$, cuja média equivalente a $5,7 \mathrm{t} \mathrm{ha-1}$ no pomar 1 e $4,7 \mathrm{t} \mathrm{ha}{ }^{-1}$ no pomar 2 . Porém, a porcentagem da massa colhida que teve tamanho adequado ao mercado de laranjas de mesa, grandes e médios, foi 33,1 e $53,8 \%$, respectivamente (Tabela 1).
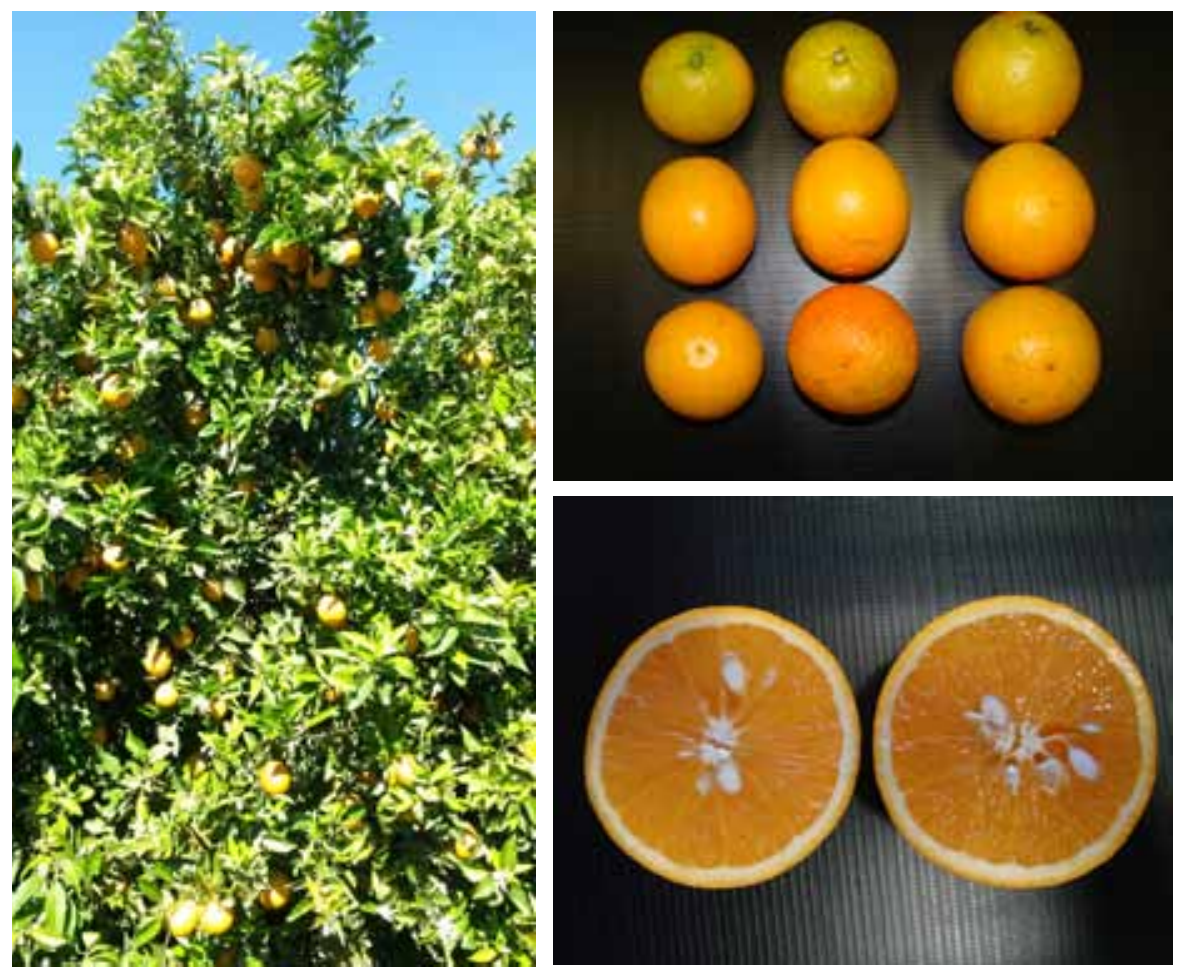

Figura 2 - À esquerda, aspecto de uma laranjeira 'Pêra' com boa carga de frutos de tamanho grande, e à direita, frutos de bom tamanho e polpa de ótimo aspecto. Chapecó, SC, 2016

Figure 2 - On the left, aspect of a 'Pêra' orange tree with a good quantity of large fruits, and on the right, fruits of good size and pulp with great appearance. Chapecó, SC, 2016
Na Tabela 2 são apresentados os dados de qualidade do suco e rendimento de suco dos frutos de cada categoria. Os valores observados de sólidos solúveis (SS) variaram de 9,7 a 13,1. A acidez titulável do suco (AT) variou de 0,63 a 1,02. A relação SS/AT mínima foi de 11,74 e a máxima de 16,35 . Os frutos renderam de 44,6 a $55,2 \%$ de suco, em massa, o que é maior que o observado no norte do Rio Grande do Sul por Frighetto et al. (2014), com laranjeira 'Valência', principal cultivar do oeste catarinense.

A Ceagesp usa como parâmetro de qualidade para laranjas de mesa o SS mínimo de 10 ㅇ Brix, a relação SS/AT mínima de 9,5 e a porcentagem de suco mínima de $45 \%$. Apenas uma planta apresentou rendimento de suco abaixo do limite e outra o SS insuficiente (em apenas uma das categorias de tamanho) (Tabela 2) - o que pode estar relacionado ao estágio de maturação. Todas as outras amostras podem ser consideradas adequadas ao mercado, se considerado o suco.

As informações obtidas neste trabalho sugerem a necessidade de se realizar experimentos avaliando todo o ciclo produtivo das plantas, comparando clones diversos de 'Pêra' com outros cultivares nas condições de Santa Catarina, incluindo tratamentos de alta densidade de plantio e ciclo mais curto. Também, por meio dos resultados obtidos, é possível observar que nos pomares estudados existem plantas com desempenho satisfatório (Figura 3), as quais possivelmente toleram o vírus da tristeza dos citros endêmico na região, cujo mecanismo envolvido necessita de maior investigação. Esses dados foram obtidos no limite superior da faixa de altitude considerada adequada para cultivo em Santa Catarina, de 600 m (KOLLER \& SOPRANO, 2013b). Se considerarmos regiões com altitude inferior que ocorrem nos vales dos rios Uruguai e Chapecó, podem ocorrer ambientes menos favoráveis ao vírus, nos quais os sintomas, incluindo os frutos pequenos, sejam menos intensos, e com isso o cultivo mais viável.

\section{Conclusão}

Nos casos em estudo, a laranjeira 'Pêra Bianchi' apresentou produtivida- 
Tabela 2 - Teor de sólidos solúveis ('Brix), acidez titulável (AT), índice ratio e rendimento de suco de laranjas 'Pêra' de três classes de tamanho, produzidas em dois pomares de Santa Catarina em 2015

Table 2 - Soluble solids content ('Brix), titratable acidity (AT), ratio and juice yield of 'Pêra' oranges of three size classes, produced in two orchards of Santa Catarina in 2015

\begin{tabular}{|c|c|c|c|c|c|c|c|c|c|}
\hline \multirow[b]{2}{*}{ Classe $^{1}$} & & \multicolumn{4}{|c|}{ Pomar $1(14 / 08 / 15)$} & \multicolumn{4}{|c|}{ Pomar $2(28 / 08 / 15)$} \\
\hline & & ${ }^{\circ}$ Brix & AT (\%) & Ratio & $\%$ suco & ${ }^{\circ}$ Brix & AT (\%) & Ratio & $\%$ suco \\
\hline \multirow[t]{4}{*}{ Grande } & Média & 10,50 & 0,68 & 15,41 & 49,9 & 10,92 & 0,74 & 14,85 & 50,7 \\
\hline & s & 0,49 & 0,04 & 1,22 & 1,80 & 0,70 & 0,06 & 0,87 & 3,16 \\
\hline & Mínimo & 9,80 & 0,63 & 14,50 & 48,0 & 9,70 & 0,66 & 13,44 & 46,9 \\
\hline & Máximo & 11,10 & 0,72 & 17,51 & 52,9 & 11,40 & 0,83 & 15,69 & 55,2 \\
\hline \multirow[t]{4}{*}{ Médio } & Média & 11,18 & 0,83 & 13,52 & 49,9 & 10,90 & 0,79 & 13,82 & 50,7 \\
\hline & s & 0,76 & 0,08 & 1,74 & 0,91 & 0,64 & 0,03 & 0,68 & 2,86 \\
\hline & Mínimo & 9,90 & 0,76 & 11,83 & 48,4 & 10,40 & 0,73 & 12,90 & 46,4 \\
\hline & Máximo & 11,80 & 0,95 & 15,60 & 50,7 & 12,00 & 0,82 & 14,61 & 53,6 \\
\hline \multirow[t]{4}{*}{ Pequeno } & Média & 12,28 & 0,96 & 12,85 & 47,9 & 11,22 & 0,81 & 14,03 & 50,2 \\
\hline & s & 0,64 & 0,08 & 1,04 & 2,41 & 0,37 & 0,13 & 2,14 & 2,51 \\
\hline & Mínimo & 11,70 & 0,83 & 11,74 & 44,6 & 10,70 & 0,69 & 11,49 & 45,9 \\
\hline & Máximo & 13,10 & 1,02 & 14,56 & 51,0 & 11,70 & 0,99 & 16,35 & 51,9 \\
\hline
\end{tabular}

(') Obtidas pela classificação mecânica por diâmetro. A calibração do equipamento foi diferente entre locais e anos.

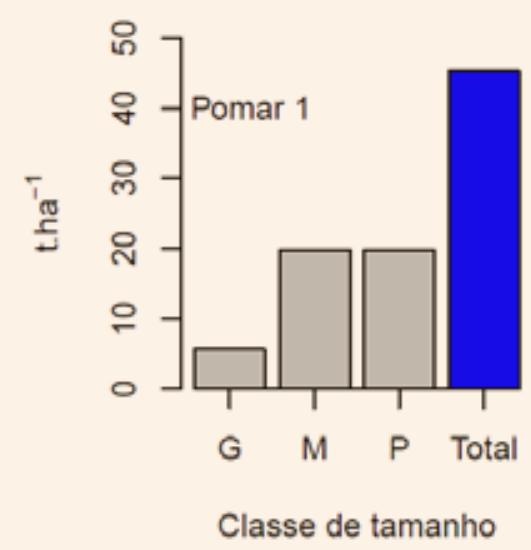

Figura 3 - Produção média anual estimada da laranjeira 'Pêra' em dois pomares do oeste catarinense avaliadas nos ciclos de produção 2014/2015 e 2015/2016. A calibração do equipamento foi diferente entre locais e anos

Figure 3 - Estimated annual average yield of 'Pêra' orange tree in two orchards in the west of Santa Catarina evaluated in the 2014/2015 and 2015/2016 production cycles. The calibration of the equipment was different between locations and years

de e qualidade de suco satisfatórias.

Grande parte dos frutos produzidos pela laranjeira 'Pêra Bianchi' nos dois pomares estudados não apresentou tamanho adequado à comercialização como fruta de mesa.

\section{Agradecimentos}

Às famílias Cunha, de Chapecó, e Sheibel, de Xaxim, por permitirem que o trabalho fosse feito em suas propriedades.

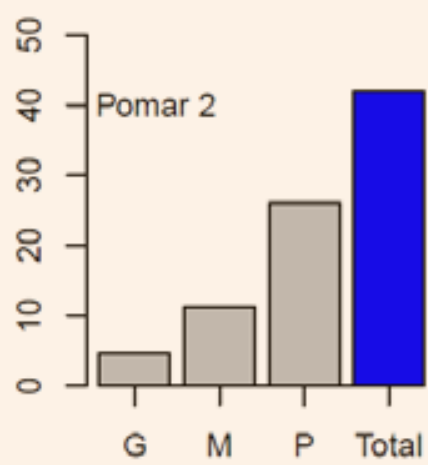

Classe de tamanho bal, v.34, n.1, p.134-142, 2012. Disponível em: $\quad<$ https://dx.doi.org/10.1590/S010029452012000100019>. Acesso em: $20 \mathrm{dez}$. 2016.

CEAGESP - Companhia de Entrepostos e Armazéns Gerais de São Paulo. Normas de classificação de citros de mesa/CEAGESP. São Paulo: CEAGESP, 2011. 11p.

FRIGHETTO, J.M.; SANTI, A.L.; PIAS, O.H.C.; TREVISAN, R.; CORASSA, G.M.; DAMIAN, J.M.; SIMON, D.H. Produtividade e qualidade físico-química de laranjas 'Valência' da região Norte do Rio Grande do Sul: mapeamento e correlação entre variáveis. Pesquisa Agropecuária Gaúcha, Porto Alegre, v.20, n. 1-2, p.25-32, 2014. Disponível em: <http:// www. revistapag.fepagro.rs.gov.br/files/PAG20V1e2.pdf>. Acesso em: 20 jun. 2017.

GIAMPANI, J.S.; TAZIMA, Z.H.; BABA, V.Y.; YADA, I.F.U.; LEITE JÚNIOR, R.P. Citrus tristeza disease severity and agronomic performance of 'Pêra' sweet orange cultivars and selections in the North and Northwest regions of the State of Paraná, Brazil. Revista Brasileira de Fruticultura, Jaboticabal, v.38, n.3, e-073, 2016. Disponível em: <http://www.scielo.br/ scielo.php?script=sci_arttext\&pid=S010029452016000300403\&lng=en\& $n r m=i s o>$. Acesso em: 23 maio 2017.

GOULART JUNIOR, R.; MONDARDO, M.; REITER, J.M.W.; MARCONDES, T.; ALVES, J.R.; PADRÃO, G.A. Relatório de projeto: fruticultura catarinense - valor da produção comercial na safra 2014/15. Florianópolis: Epagri, 2016. (Série Boletim Didático).KOLLER, O.L.; 
SOPRANO, E. Desenvolvimento e produção de cultivares cítricas em Santa Catarina, Brasil. Ciência e Prática, Lavras, v.17, n.3, p.208214, 1993.

KOLLER, O.L.; SOPRANO, E. Principais cultivares cítricos. In: KOLLER, O.L. (Org.). Citricultura catarinense. Florianópolis: Epagri, 2013a. p.57-120.

KOLLER, O.L.; SOPRANO, E. Planejamento do pomar. In: KOLLER, O.L. (Org.). Citricultura Catarinense. Florianópolis: Epagri, 2013b. p.41-55.

KOLLER, O.L.; SOPRANO, E.; COSTA, A.C.Z. Avaliação de porta-enxertos para laranjeira 'Hamlin' em Santa Catarina. Ceres, Viçosa, v.47, n.271, p.325-336, 2000.

MARTINS, F.T. Comportamento de laranjeira 'Valência' e tangerineira 'Montenegrina' propagadas por estaquia e enxertia. 2005. 77f. Dissertação (Mestrado em Fitotecnia) Universidade Federal do Rio Grande do Sul, Porto Alegre, 2005.

SARTORI, I.A.; KOLLER, O.K.; SCHWARZ, S.F.; BENDER, R.J.; SCHÄFER, G. Maturação de frutos de seis cultivares de laranjas-doces na depressão central do Rio Grande do Sul. Revista Brasileira de Fruticultura, Jaboticabal, v.24, n.2, p.364-369, 2002.

SCHINOR, H.S.; AGUILAR-VILDOSO, C.I.; MOURÃO FILHO, F.A.A. Caracterização agronômica de seleções de laranjeira Pêra e sua relação com a mancha preta dos citros. Laranja, Cordeirópolis, v.30, n.1-2, p.75-96, 2009. Disponível em: <http://revistalaranja.centrodecitricultura.br/edicoes/12/17/2009 6.pdf>. Acesso em: 3 out. 2016.

SOUZA, A.A.; MÜLLER, G.W. A premunização no controle da tristeza dos citros. Laranja, Cordeirópolis, v.27, n.1, p.57-70, 2006. Disponível em: <http://revistalaranja.centrodecitricultura.br/edicoes/9/14/v27\%20n1\%20 art05_286-premuniza\%E7\%E3o.pdf>. Acesso em: 3 out. 2016.

TAZIMA, Z.H.; NEVES, C.S.V.J.; YADA, I.F.U.; LEITE JUNIOR, R.P. Produção e qualidade dos frutos de clones de laranjeira-'Pera' no norte do Paraná. Revista Brasileira de Fruticultura, Jaboticabal, v.32, n.1, p.189-195, 2010. Disponível em: <http://www.scielo.br/pdf/ rbf/v32n1/aop00910.pdf >. Acesso em: 2 jun. 2017.

THEODORO, G.F.; KOLLER, O.L. Descrição e manejo integrado de doenças. In: KOLLER, O.L. (Org.). Citricultura catarinense. Florianópolis: Epagri, 2013. p.175-246.
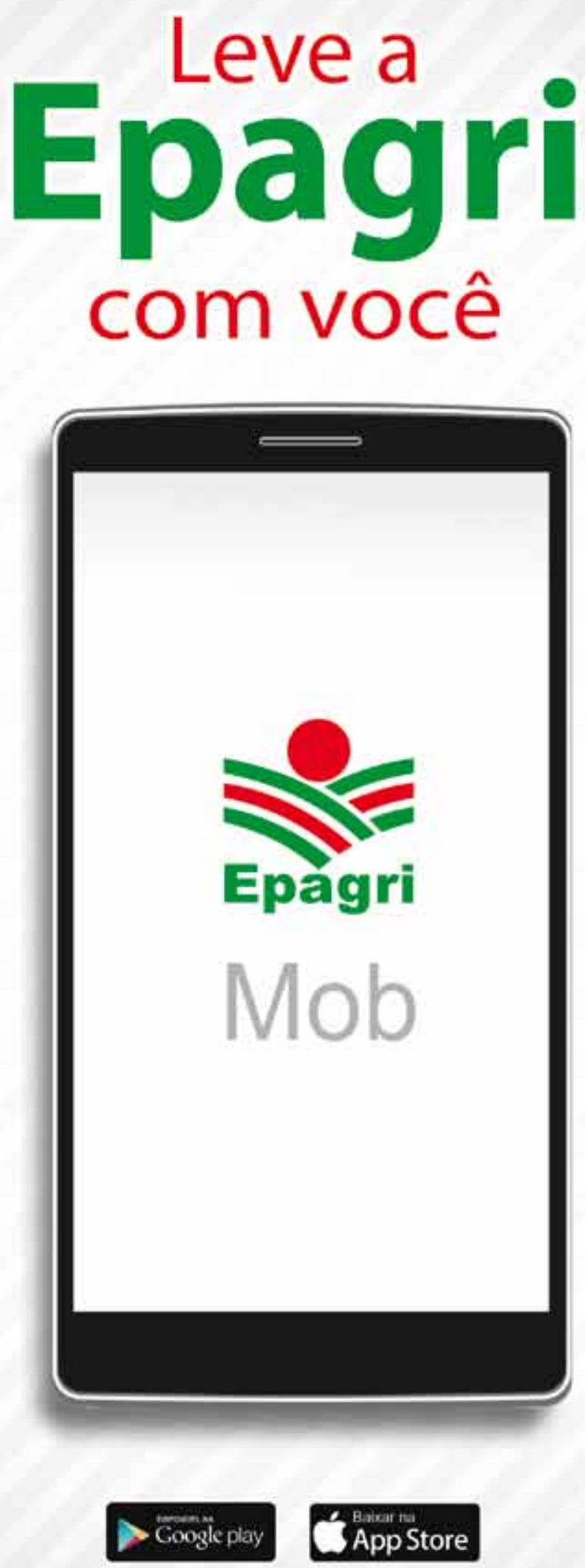